\title{
INVESTIGAÇÃO DIALÓGICA NA SALA DE AULA DE CIÊNCIAS: Etnopesquisa-Formação com Professores de Ciências da Natureza
}

\author{
Charles dos Santos Guidotti ${ }^{1}$ \\ Valmir Heckler ${ }^{2}$
}

\begin{abstract}
RESUMO
O artigo apresenta compreensões de uma etnopesquisa-formação com professores acerca da investigação dialógica na sala de aula de Ciências. Abrange a constituição do campo empírico, delimitada à análise de 43 relatos produzidos por professores do campo da Ciências da Natureza (Química, Física, Biologia e Ciências) em formação nas edições dos anos 2016 e 2017 do Projeto de Extensão Cirandar, desenvolvido em uma Universidade Pública Brasileira em parceria com Escolas de Educação Básica. A análise é feita a partir da linguagem expressa nas produções textuais, com base na questão norteadora do estudo: O que é isso que se mostra da investigação nos relatos dos professores de Ciências em formação no Cirandar? Assume-se a etnopesquisa-formação em uma abordagem fenomenológica hermenêutica como meio de construção epistemológica. As informações foram analisadas seguindo os princípios da Análise Textual Discursiva (ATD), em que emergiram quatro categorias finais. Neste texto, apresentamos compreensões referentes à categoria IV) Investigação dialógica na sala de aula de Ciências, em que a investigação dialógica é assumida pelo coletivo de professores analisado como estratégia didático-pedagógica desencadeada pela problematização, com questionamentos dos estudantes e professores ao operar, de forma coletiva, informações e linguagem científica no constituir, negociar e comunicar significados na sala de aula de Ciências.
\end{abstract}

Palavras-chave: Investigação dialógica. Educação em Ciências. Etnopesquisa-formação. Análise Textual Discursiva (ATD).

\section{DIALOGUE INQUIRY IN SCIENCE CLASSROOM: ETHNOP-RESEARCH TRAINING WITH NATURAL SCIENCE TEACHERS}

\section{ABSTRACT}

The article presents understandings of an ethno-research-formation with teachers, about dialogical research in the science classroom. It covers the constitution of the empirical field, delimiting the analysis of 43 reports produced by professors of the field of Natural Sciences (Chemistry, Physics, Biology and Sciences) under formation in the 2016 and 2017 editions of the Cirandar extension project: research circles since the school, developed at a Brazilian Public University in partnership with Basic Education Schools. The analysis is based on the language expressed in the textual productions, in which empirical information emerged from the research, based on the guiding question of the study: What is this from research in the reports of science teachers in Cirandar? It is assumed that ethno-research-formation in a hermeneutic phenomenological approach as a means of epistemological construction. The information was analyzed following the principles of Discursive Textual Analysis (ATD), in which four final categories emerged. In this text, we present understandings related to category IV) Dialogical inquiry in the science classroom, which shows the dialogical investigation is assumed by the analyzed teachers' collective, as a didactic-pedagogical strategy triggered by the problematization, with questions from students and teachers when operating, collectively, information. and scientific language in constituting, negotiating and communicating meanings in the science classroom.

Keywords: Dialogical inquiry. Science education. Ethno-research-training. Discursive Textual Analysis (ATD).

RECEBIDO EM: 22/1/2020

ACEITO EM: 23/3/2020

\footnotetext{
1 Autor correspondente. Universidade Federal do Rio Grande. Campus Santo Antônio da Patrulha/RS, Brasil. http://lattes.cnpq. br/0824536923794686. https://orcid.org/0000-0002-5483-1550. charles.guidotti@furg.br

2 Universidade Federal do Rio Grande. Rio Grande/RS, Brasil. http://lattes.cnpq.br/0446681267010261. https://orcid.org/0000-0002-38383903
} 
O significado da palavra investigação é polissêmico, portanto, dependendo de quem o utiliza e do contexto que o envolve, pode assumir diferentes significados e enfoques. Tomemos, inicialmente, o significado da palavra investigação no dicionário da Língua Portuguesa (FERREIRA, 2010), que é apresentado como: "1. Ato ou efeito de investigar, busca, pesquisa. 2. Indagação minuciosa; indagação, inquirização". Com isso, nota-se que investigar significa fazer perguntas, buscar informações, construir e reconstruir respostas argumentadas. Assumindo como enfoque central, em uma abordagem sociocultural, a compreensão de que o desenvolvimento do conhecimento acontece na interação entre pessoas que fazem coisas em conjunto (WELLS, 2016), o investigar no contexto da Educação em Ciências abrange um movimento de problematização que implica levar em consideração a experiência, a fala, a leitura e a escrita dos sujeitos envolvidos.

Neste contexto, apresentamos, com este artigo, compreensões sobre a investigação dialógica na sala de aula de Ciências, recorte de uma pesquisa de doutoramento. A referida pesquisa é orientada pela seguinte interrogação: $O$ que é isso que se mostra da investigação nos relatos dos professores de Ciências em formação no Cirandar? Ao questionarmos o que é que se mostra, dedicamo-nos no estudo a situar um fenômeno (BICUDO, 2011); logo, assumimos o fenômeno como aquilo que se revela na experiência vivida pelos pesquisadores a partir da descrição do campo empírico.

As referidas compreensões são constituídas a contar da análise de 43 relatos produzidos por professores da área da Ciências da Natureza (Física, Química, Biologia e Ciências), nas edições 2016 e $2017^{3}$ do Projeto de Extensão Cirandar: rodas de investigação desde a escola ${ }^{4}$ da Universidade Federal do Rio Grande (Furg). Iniciado em 2012, com o objetivo de discutir a reestruturação curricular proposta pela Secretária de Educação do Estado do Rio Grande do Sul, o Cirandar constitui-se em um espaçotempo ${ }^{5}$ de formação acadêmico-profissional de professores da universidade, da escola e de licenciandos. Neste espaçotempo, que tem duração de aproximadamente oito meses de formação, os professores são desafiados a partilhar, pela escrita, experiências de sala de aula que considerem importante problematizar para compreender melhor.

Nesse sentido, no Cirandar o escrever assume função epistêmica, em um processo recursivo do professor em formação na busca de expressar compreensões sobre o seu objeto em estudo. Ancorados em Duhalde (1999), entendemos que esse objeto é um produto do pensamento e da concepção que, por sua vez, oportuniza aos professo-

\footnotetext{
3 Optou-se por delimitar o olhar para as edições de 2016 e 2017 desse processo acadêmico-profissional de formação de professores da área de Ciências da Natureza, uma vez que, nas referidas edições do Cirandar, os pesquisadores estiveram efetivamente inseridos no percurso formativo, com o objetivo de ampliar compreensões em torno das suas salas de aulas.

4 Informações do projeto em: https://cirandar.furg.br/

Na escrita da pesquisa empregamos o termo espaçotempo a partir da perspectiva de Alves (2015) e Diniz-Pereira e Lacerda (2009). Esse modo de escrever mostrou-se necessário, uma vez que no Cirandar os professores, cada um em seu espaço e em seu tempo, desenvolvem as suas investigações que são partilhadas no momento em que o espaço e o tempo cronológico se tornam o mesmo. O termo também é empregado para registrar a simultaneidade entre investigação e formação, superando a dicotomização entre a prática/teoria e a teoria/prática, entre o pensar/fazer e o fazer/pensar. Além disso, utilizamos a grafia para registrar que esse tipo de formação acadêmicoprofissional, proposta pelo projeto Cirandar, oportuniza múltiplas interações entre escola e universidade, não existindo, assim, um tempo e um espaço específicos para a formação. Neste contexto, reconhecemos a prática docente como um espaçotempo de investigação e formação coletiva.
} 
res (re)construírem um marco teórico que permite planejar, planificar, produzir e projetar propostas educativas, levando em conta as complexas características que envolvem a realidade profissional.

Além disso, o processo formativo proposto no âmbito do projeto acontece em coletivo de professores, uma vez que as escritas são partilhadas entre pares num processo de discussão para a construção dos relatos, favorecendo, assim, que os professores percebam o que e como escrever. Nesse movimento, os professores em formação aperfeiçoam e desenvolvem conhecimentos, envolvendo-se em um processo coletivo de reflexão discursiva acerca de suas ações. É nesse espaçotempo colaborativo que os professores de diferentes níveis de ensino e licenciandos interagem, na maior parte do tempo, por intermédio de correio eletrônico. O projeto prevê ainda outros dois momentos de interação por meio dos encontros presenciais, no início e no final do percurso formativo. Nesses encontros, o professor participante teoriza, indaga e é indagado sobre as suas experiências profissionais.

Caracterizamos o estudo como uma etnopesquisa-formação (MACEDO, 2010), em uma abordagem fenomenológica hermenêutica (BICUDO, 2011), em que as informações são analisadas seguindo os princípios da Análise Textual Discursiva (ATD) (MORAES; GALIAZZI, 2016). A partir de Macedo (2010), registramos que a natureza desse tipo de pesquisa-ação, assumida como etnopesquisa-formação, é qualitativa, de inspiração etnometodológica e de tradição etnográfica. Segundo Barbosa e Barbosa (2008 ), a etnometodologia destaca-se por ser uma teoria social voltada para o interesse da compressão da ordem sociocultural, a partir da valorização das ações cotidianas dos autores envolvidos nos processos sociais. Desse modo, com a linguagem manifestada na forma escrita dos professores de Ciências da Natureza em formação no Cirandar, estamos atentos ao contexto em que as experiências se passam, ou seja, nas salas de aulas de Ciências.

\section{METODOLOGIA}

Orientado pela perspectiva fenomenológica hermenêutica, o compreender é assumido, nesta pesquisa, como um modelo teórico que se desenvolve gradualmente ao longo do estudo a partir das intuições que as informações recolhidas possibilitam (MORAES; GALIAZZI, 2016). A perspectiva fenomenológica hermenêutica engloba o “[...] movimento de trabalhar com sentidos e significados que não se dão em si, mas que vão se constituindo e se mostrando em diferentes modos, de acordo com a perspectiva do olhar e na temporalidade histórica de suas durações [...]" (BICUDO, 2011, p. 41). Seguindo essa perspectiva, no estudo alcançamos a compreensão a contar de um complexo e intenso processo de interpretação dialógica de experiências de professores em formação, incluindo os pesquisadores ${ }^{6}$, contidas na linguagem comunicada por meio da escrita.

Quando mencionamos professores em formação no projeto Cirandar, entende-se por professores participantes da comunidade em formação no referido projeto, incluindo o pesquisador que começa a participar desse processo formativo a contar da edição do ano 2016. 
Assumimos as compreensões teórico-práticas expressas em linguagem proposicional, comunicadas nas produções textuais dos professores em formação como resultado de um processo investigativo em torno de um "objeto aperfeiçoável" (WELLS, 2016). Esse objeto, no contexto do Cirandar, assume múltiplas formas, envolvendo o registro e a proposição de atividades de ensino e as investigações em diferentes espaços educacionais, os pensamentos dos professores em formação a respeito da docência da própria formação, ensino e aprendizagem, políticas públicas, entre outros objetos emergentes. Com isso, seguindo as ideias de Bicudo (2011), o pesquisador realiza inúmeras leituras dos relatos, com o intuito de que as experiências vividas pelos sujeitos sejam existencialmente compreendidas.

Desenvolvemos a análise das informações seguindo os princípios da Análise Textual Discursiva (ATD) (MORAES; GALIAZZI, 2016). Utilizamos na análise uma sequência recursiva com três componentes: a desconstrução dos relatos do corpus (unitarização), o estabelecimento de relações entre os elementos unitários (categorização) e o captar emergente em que novas compreensões são comunicadas e validadas em interlocuções com a construção de significados no metatexto emergente.

No movimento de unitarização os pesquisadores examinam os relatos em seus detalhes, fragmentando-os com o objetivo de atingir unidades de sentidos referentes ao fenômeno em estudo. O Quadro 1 é um recorte da organização das informações analisadas neste estudo.

Quadro 1 - Recorte das unidades de sentido e as suas codificações a partir do corpus de análise

\begin{tabular}{|c|c|c|c|}
\hline CÓDIGO & UNIDADE DE SENTIDO & TÍTULO & $\begin{array}{l}\text { CATEGORIA } \\
\text { INICIAL }\end{array}$ \\
\hline R7.1 & $\begin{array}{l}\text { A relação com o estágio me acompanha desde } \\
\text { minha formação inicial, não apenas por ser } \\
\text { exigência para receber o título de "professora", } \\
\text { mas por proporcionar diversas experiências } \\
\text { como de ser muito bem acolhida pela professora } \\
\text { regente da turma em que realizei o estágio, assim } \\
\text { como os demais professores da escola. }\end{array}$ & $\begin{array}{l}\text { A investigação } \\
\text { do professor a } \\
\text { partir da sua } \\
\text { experiência de } \\
\text { sala de aula }\end{array}$ & 16 \\
\hline R8.4 & $\begin{array}{l}\text { Ao refletir sobre as respostas desses alunos e } \\
\text { recordar das nossas aulas, lembro que fazíamos de } \\
\text { cada aula um lugar de escuta e de discussão, em que } \\
\text { a participação de cada um fazia "a diferença", pois, a } \\
\text { partir dela, poderiam surgir temas para discutirmos } \\
\text { nas aulas. Além disso, em cada encontro um dos } \\
\text { alunos apresentava alguns aspectos dos textos a } \\
\text { respeito de experimentação, de legislação e, a partir } \\
\text { daí, discutíamos no grupo. Dessa forma, cada um } \\
\text { tornava-se corresponsável pela aula. }\end{array}$ & $\begin{array}{l}\text { A escuta do } \\
\text { professor e a fala } \\
\text { do estudante } \\
\text { possibilitam } \\
\text { torná-los } \\
\text { corresponsáveis } \\
\text { pela aula }\end{array}$ & 21 \\
\hline R9.9.CH & $\begin{array}{l}\text { A investigação do professor mostra-nos que os } \\
\text { professores da escola buscam informações para } \\
\text { as suas formações em eventos a serem realizados } \\
\text { na própria escola, com palestras e espaços de } \\
\text { compartilhamento de experiências narrados em } \\
\text { portfólios. }\end{array}$ & $\begin{array}{l}\text { Os professores } \\
\text { da escola em } \\
\text { formação } \\
\text { continuada } \\
\text { buscam a } \\
\text { colaboração de } \\
\text { outros autores } \\
\text { externos }\end{array}$ & 11 \\
\hline
\end{tabular}




\begin{tabular}{|c|l|c|c|}
\hline R11.5 & $\begin{array}{l}\text { Nessa perspectiva dialógica, o debate envolve } \\
\text { não apenas a participação dos estudantes, } \\
\text { mas a sua própria organização, a construção } \\
\text { do ator social e da respectiva postura a ser } \\
\text { assumida. Isso envolve pesquisa e construção de } \\
\text { argumentos fundamentados, abertura ao diálogo, } \\
\text { respeito a opiniões divergentes e construção de } \\
\text { conhecimento. Isso será detalhado na sequência. }\end{array}$ & $\begin{array}{c}\text { O debate em sala } \\
\text { de aula envolve a } \\
\text { participação ativa } \\
\text { dos estudantes } \\
\text { na construção } \\
\text { de argumentos } \\
\text { a contar da } \\
\text { pesquisa }\end{array}$ & 29 \\
\hline R15.2 & $\begin{array}{l}\text { O relato apresenta a ideia de priorizar a ansiedade } \\
\text { e o interesse de uma turma, tendo como objetivos } \\
\text { construir, conhecer, entender e ressignificar } \\
\text { conceitos e ideias acerca do tema, elaborar } \\
\text { hipóteses explicativas ao foco de investigação, } \\
\text { conhecer e comparar diferentes aspectos } \\
\text { relacionados ao caracol. }\end{array}$ & $\begin{array}{c}\text { A inva a } \\
\text { partir do interesse } \\
\text { e da curiosidade } \\
\text { dos estudantes }\end{array}$ & 3 \\
\hline
\end{tabular}

Fonte: Os autores.

O Quadro 1 exemplifica, por meio de um recorte com seis unidades, do total de 250 unidades desenvolvidas no estudo, a maneira que sistematizamos a análise das informações. As unidades de sentido, expressas na segunda coluna do Quadro, são o resultado da desconstrução dos 43 relatos selecionados. Para cada unidade atribuímos um código, como o R8.1. Dessa forma, podemos identificar que essa unidade de sentido foi obtida no relato 8 , sendo a primeira unidade deste texto. Além disso, o processo de análise pela ATD possibilita aos pesquisadores criarem as suas próprias unidades de sentido. Para identificar as unidades de autoria dos pesquisadores, utilizamos uma letra, tal como R9.9.CH. Esse código significa que esta unidade não é localizada diretamente no relato, porém expressa sentidos implícitos nas proximidades da unidade R9.9, por exemplo. Esse movimento de codificar as unidades possibilitou, ao longo do estudo, retornamos sempre que necessário ao relato de origem da unidade.

A terceira coluna apresenta o título da unidade de sentido atribuída pelos pesquisadores. Esse processo de interpretação e compreensão das unidades depende dos conhecimentos teóricos do pesquisador, bem como de unidades de sentido teóricas incluídas no processo de análise. Com isso, de acordo com Moraes e Galiazzi (2016), a partir de um mesmo conjunto de significantes é possível construir uma multiplicidade de significados, que tem sua origem nos diferentes pressupostos teóricos que o pesquisador adota.

Após o processo de unitarização, inicia-se o movimento de categorização. Esse movimento acontece a partir da comparação dos títulos atribuídos em cada unidade de sentido, levando ao agrupamento das unidades que expressam elementos semelhantes, dando origem, desse modo, a 27 categorias iniciais. O Quadro 2 apresenta um recorte dessa organização.

Quadro 2 - Categorias iniciais interligadas ao código da categoria final

\begin{tabular}{|c|l|c|}
\hline $\begin{array}{c}\text { CATEGORIA } \\
\text { INICIAL }\end{array}$ & \multicolumn{1}{|c|}{ TÍTULO } & $\begin{array}{c}\text { CATEGORIA } \\
\text { FINAL }\end{array}$ \\
\hline 1 & Perspectiva teórica da aprendizagem & $\mathrm{C}$ \\
\hline 2 & Pesquisa-ação colaborativa & $\mathrm{B}$ \\
\hline 3 & O diálogo no Ensino de Ciências & $\mathrm{D}$ \\
\hline
\end{tabular}




\begin{tabular}{|c|c|c|}
\hline 4 & Contexto social nas metodologias do Ensino de Ciências & $\mathrm{D}$ \\
\hline 5 & Saberes teóricos e práticos do professor & $\mathrm{C}$ \\
\hline 6 & A leitura em sala de aula & $\mathrm{D}$ \\
\hline 7 & A fala dos estudantes na avaliação do professor & $\mathrm{C}$ \\
\hline 8 & A investigação com o registro da experiência & A \\
\hline 9 & Parceria entre professores formadores e licenciandos & B \\
\hline 10 & O diálogo na formação inicial & $\mathrm{B}$ \\
\hline 11 & A prática reflexiva em coletivos de professores & $\mathrm{B}$ \\
\hline 12 & Parceria entre escola e universidade* & $\mathrm{B}$ \\
\hline 13 & Os registros do professor investigador & A \\
\hline 14 & O diálogo na reestruturação curricular & $\mathrm{C}$ \\
\hline 15 & O diálogo entre professores & $\mathrm{B}$ \\
\hline 16 & A experiência da sala de aula gera conhecimento & A \\
\hline 17 & Planejamento coletivo de professores & $\mathrm{C}$ \\
\hline 18 & O compartilhar materiais didáticos & C \\
\hline 19 & A investigação narrativa & A \\
\hline 20 & A investigação do professor a partir do diálogo em sala de aula & A \\
\hline 21 & A fala do estudante em sala de aula & $\mathrm{D}$ \\
\hline 22 & A formação continuada de professores e as políticas públicas & $\mathrm{B}$ \\
\hline 23 & O aperfeiçoamento da prática pedagógica & $\mathrm{C}$ \\
\hline 24 & A formação inicial de professores e as políticas públicas & $\mathrm{B}$ \\
\hline 25 & A pergunta na formação inicial de professores & $\mathrm{B}$ \\
\hline 26 & A investigação em sala de aula & $\mathrm{D}$ \\
\hline 27 & O registro em sala de aula do estudante & $\mathrm{D}$ \\
\hline 28 & A pergunta do estudante em sala de aula & $\mathrm{D}$ \\
\hline 29 & Estratégias de ensino & $\mathrm{D}$ \\
\hline 30 & A linguagem no constituir e negociar significados & $\mathrm{D}$ \\
\hline 31 & Alteridade na formação de professores & $\mathrm{B}$ \\
\hline 32 & $\begin{array}{l}\text { Formação de professores com o desconstruir e reconstruir } \\
\text { práticas de ensino com fundamento da (e com a) teoria }\end{array}$ & B \\
\hline
\end{tabular}

Fonte: Os autores.

Cada categoria corresponde a um conjunto de unidades de sentido que expressa ideias semelhantes. Durante todo o processo de análise, a ATD desafia os pesquisadores a construírem sínteses dos significados. As sínteses ajudaram a desenvolver uma análise auto-organizada de qualidade e com clareza. Nessa etapa do estudo, as sínteses aglutinam as ideias enunciadas nas unidades de sentido que deram origem à categoria que pertence.

A partir das categorias iniciais retomamos o processo de comparação e aglutinação, e assim chegamos à construção das categorias intermediárias, conforme mostra o Quadro 3:

Quadro 3 - Categorias intermediárias pela organização das categorias iniciais

\begin{tabular}{|c|l|c|}
\hline $\begin{array}{c}\text { CÓDIGOS DAS } \\
\text { CATEGORIAS INICIAIS }\end{array}$ & \multicolumn{1}{|c|}{ CATEGORIA INTERMEDIÁRIA } & $\begin{array}{c}\text { CATEGORIA } \\
\text { FINAL }\end{array}$ \\
\hline 8,13 & Os registros de ações de sala de aula do professor & $\mathrm{A}$ \\
\hline 16,20 & $\begin{array}{l}\text { A experiência de sala de aula oportuniza o } \\
\text { aperfeiçoamento profissional a partir do diálogo }\end{array}$ & $\mathrm{A}$ \\
\hline
\end{tabular}




\begin{tabular}{|c|l|l|}
\hline 19 & A investigação narrativa & A \\
\hline $10,11,15,25,31$ & A prática reflexiva em coletivos de professores & B \\
\hline 9,12 & Parceria entre escola e universidade & B \\
\hline 22,24 & Formação de professores e as políticas públicas & B \\
\hline 2,32 & Pesquisa-ação colaborativa & B \\
\hline 1,5 & Saberes teórico-práticos do professor & C \\
\hline 17,18 & Planejamento coletivo de professores & C \\
\hline 14 & O diálogo na reestruturação curricular & C \\
\hline 7,23 & O aperfeiçoamento da prática pedagógica & C \\
\hline 6,21 & A leitura e a fala dos estudantes nas aulas de Ciências & D \\
\hline $3,4,27,28,30$ & A linguagem no constituir e negociar significados & D \\
\hline 26,29 & A investigação como estratégia de ensino em sala de aula & D \\
\hline
\end{tabular}

Fonte: Os autores.

A partir das 14 categorias intermediárias foram construídas quatro categorias finais:

Quadro 4 - Categorias finais interligadas aos códigos das categorias iniciais

\begin{tabular}{|c|c|c|}
\hline $\begin{array}{c}\text { CÓDIGO DAS CATEGORIAS } \\
\text { INICIAIS }\end{array}$ & $\begin{array}{c}\text { CÓDIGO DA } \\
\text { CATEGORIA FINAL }\end{array}$ \\
\hline $8,13,16,20,19$ & $\begin{array}{c}\text { Investigação do professor com registros da } \\
\text { experiência }\end{array}$ & $\mathrm{A}$ \\
\hline $\begin{array}{c}2,9,10,11,12,15,22,24, \\
25,31,32\end{array}$ & $\begin{array}{c}\text { Formação de professores no coletivo da } \\
\text { escola e da universidade }\end{array}$ & $\mathrm{B}$ \\
\hline $\begin{array}{c}1,5,7,14,17,18,23 \\
\text { Aperfeiçoamento de saberes do } \\
\text { professor ao planejar, com diálogo, ações } \\
\text { investigativas }\end{array}$ & $\mathrm{D}$ \\
\hline $30,6,21,26,27,28,29$, & $\begin{array}{c}\text { Investigação dialógica na sala de aula de } \\
\text { Ciências }\end{array}$ & \\
\hline
\end{tabular}

Fonte: Os autores.

A partir do caminho metodológico descrito, apresentamos, neste estudo, compreensões construídas em torno da categoria Investigação dialógica na sala de aula de Ciências.

\section{INVESTIGAÇÃO DIALÓGICA NA SALA DE AULA DE CIÊNCIAS}

As produções escritas dos professores mostram a investigação como estratégia didático-pedagógica em sala de aula. A busca por respostas a inquietações, numa perspectiva dialógica, desafia professores e estudantes a se envolverem num contínuo movimento de fala, leitura e escrita. Abordaremos a investigação dialógica na sala de aula de Ciências, em que a problematização, a pergunta, a linguagem, a fala, a escrita e as estratégias de ensino são aspectos a serem significados.

A escrita na análise desta categoria está interligada a três categorias intermediárias:

- A leitura e a fala nas aulas de Ciências;

- A linguagem no constituir e negociar significados;

- A investigação como estratégia de ensino em sala de aula. 
Nesta análise, as categorias intermediárias referem-se aos aspectos comunicados pelos professores de Ciências, participantes do Cirandar, para que os seus estudantes se engajem ativamente em atividade de investigação no ensino de Ciências no contexto da sala de aula. Enquanto aspecto central da análise, a investigação mostra-se como estratégia didático-pedagógica, num processo que abrange a exploração de inquietações e pensamentos de estudantes e professores, bem como as ações na sala que envolvam evidências, artefatos culturais e práticas específicas. Além disso, assumimos que esse processo acontece no diálogo entre estudantes e professores, com vista ao desenvolvimento da alfabetização científica.

Transformar a sala de aula em um ambiente investigativo, com trabalho coletivo, constitui-se em um grande desafio, por que significa, desde logo, não privilegiar o professor, mas o estudante (DEMO, 1997). Ao discorrer sobre a proposição de uma unidade de aprendizagem no Ensino Médio, Lima-R11 ${ }^{7}$ apresenta o debate em sala de aula como possibilidade de engajar os estudantes em um processo que busca a construção de argumentos. O debate, proposto pelo professor, está organizado em torno de uma problematização que envolve a instalação de um empreendimento de mineração em sua cidade.

Apoiados em Freire (2017), compreendemos que em uma educação problematizadora, dialógica por excelência, os conteúdos do currículo de Ciências organizam-se e se constituem na visão de mundo dos estudantes. Nesse cenário, seguindo as ideias de Delizoicov (2001), a problematização, proposta pelos professores, deve ter potencial de gerar nos estudantes a necessidade de apropriação de um conhecimento que eles ainda não têm e que ainda não foi apresentado pelo professor (p. 133). Sendo assim, significamos que, a partir da problematização em sala de aula, processos de investigação podem ser desencadeados com a participação ativa dos estudantes e professores.

Na sala de aula relatada por Galiazzi-R29 observamos que esse movimento de problematização acontece a partir do desafio dos estudantes ${ }^{8}$ ao escolherem e descreverem objetos de afeto que, de algum modo, tenham impactado as suas vidas.

[...] deste objeto que, de certa forma, também apresenta o aluno, é que os conteúdos estão sendo relacionados, seja pela disciplina de CTS, ou pela de Sociologia, ou pela disciplina de Filosofia (Galiazzi-R29).

Nesse contexto, identificamos que é desde o contar de um objeto de afeto dos estudantes que os conteúdos de três disciplinas começam a ser organizados e problematizados. Nessa sala de aula, os objetos que se busca conhecer melhor, a partir de uma descrição inicial, em termos histórico, científico, filosófico e sociológico, produzem efeitos de reflexão da realidade dos estudantes e professores. O referido elemento é observado na escrita da professora Galiazzi-R29, ao afirmar que,

\footnotetext{
Ao longo do texto conservamos os nomes originais dos autores dos relatos, uma vez que essas informações estão registradas no AVA do projeto, que é de acesso livre. Além disso, disponibilizamos as referências dos relatos analisados no link: https://goo.gl/ULC5pA.

8 Nesse caso, professores em formação inicial no curso de Licenciatura em Ciências na modalidade EaD da Universidade Federal do Rio Grande (Furg).
} 
[...] a cada um, uma realidade, embora o real possa ser o mesmo. É isso que a descrição quer fazer. E então a interdisciplina estará perpassada pelos tipos de conhecimento que estes objetos carregam.

Diante disso, o objeto de afeto é considerado um objeto a ser compreendido ao longo do processo formativo, a ser aperfeiçoado na perspectiva de uma investigação dialógica (WELLS, 2016). A análise da escrita de Galiazzi-R29 evidencia que as compreensões em torno do referido objeto, de cada participante da sala de aula, acontecem pelo diálogo entre estudantes e professores, mesmo que geograficamente distantes. A escolha do objeto aperfeiçoável fornece aos estudantes e professores um foco no desenvolvimento de investigações com interações discursivas em sala de aula, especialmente a partir das compreensões iniciais dos estudantes. Para Wells (2016), em cada etapa a consideração crítica do objeto é suscetível de levantar novas problematizações e motivar a revisão, chamando, assim, para posterior construção do conhecimento. Além disso, de acordo com Sá, Lima e Aguiar Jr. (2011), é consenso entre professores e pesquisadores que a aprendizagem dos estudantes é mais efetiva quando lhes é oportunizado realizar investigações, trazendo para a sala de aula as suas experiências pessoais.

Nessa perspectiva, segundo Lemke (1997), significar é um processo de relacionar as coisas ao contexto, fazendo com que as ações e os eventos sejam significativamente contextualizados. Isso implica afirmar que o ensino de Ciências desafia ser planejado de forma a se articular ao mundo vivencial dos estudantes. No relato de Lima-R11, a referida proposição mostra-se interligada ao enfoque Ciências, Sociedade e Tecnologia (CTS), como um dos aspectos a ser levado em conta na constituição de atividades investigativas em sala de aula:

[...] considerando que o enfoque CTS pode trazer uma importante contribuição ao meu propósito de discutir Ecologia com vistas a permitir que os estudantes conheçam seu entorno e saibam se posicionar criticamente frente aos desafios ambientais da atualidade, organizei a atividade que relato (Lima-R11, grifo nosso).

Ao considerar o enfoque CTS, os professores estão assumindo o papel conscientizador que o conhecimento precisa ter a ser abordado em sala de aula. Nas palavras de Freire (2014), trata-se de promover uma educação problematizadora, que faz oposição à educação bancária. Nos relatos analisados observamos que a problematização proposta busca oportunizar aos estudantes conhecerem a sua realidade, além de torná-los sujeitos mais críticos dessa. Assim, a educação problematizadora, em torno de um objeto aperfeiçoável, desafia estudantes e professores a constituírem coletivos de indagação e investigação.

De acordo com Solino e Gehlen (2015), numa perspectiva freiriana, a natureza do termo problema está relacionada a um determinado momento histórico, fruto das desigualdades sociais que representam contradições vivenciadas pelos estudantes. Desse modo, é necessário que o problema formulado tenha significado para eles, de maneira a inquietá-los e desafiá-los a desenvolver argumentos por intermédio da investigação. Concordamos com Ricardo (2010), que afirma que uma situação problema que não tenha significado, ou que não esteja clara, corre o risco de esvaziar-se em trabalhos infrutíferos. 
Assim, é a partir do problema sintetizado em um tema gerador que os estudantes do professor Lima-R11 iniciam o processo de busca e ampliação de argumentos a favor ou contra a construção de um empreendimento do setor de mineração no município. Nesse sentido, seguindo as ideias de Freire (2017), compreendemos que a investigação do tema oportuniza inserir os estudantes numa forma crítica e coletiva de pensarem o seu mundo e, com isso, significar conceitos das Ciências em um contexto local.

Outro aspecto que se mostra no relato de Lima-R11, diz respeito a organização da sala de aula. Seguindo essa perspectiva, os estudantes, organizados em pequenos grupos, têm a autoridade de buscar soluções para o problema proposto. $O$ trabalho em equipe coloca a necessidade de exercitar a cidadania coletiva e organizada, à medida que se torna crucial argumentar na direção dos consensos possíveis (DEMO, 1997, p. 18). Sendo assim, cada membro do grupo tem a responsabilidade de colaborar intelectualmente com os demais para subsidiar a postura assumida, em que os mais experientes em cada temática colaboram na construção de argumentos dos menos experientes.

De acordo com Wells (2016), quando aos estudantes é dada a oportunidade de participarem da resolução de problemas de forma colaborativa, eles reconhecem que suas contribuições têm consequências para a decisão que é conjuntamente construída (p. 81). Registramos, entretanto, que o ensino de Ciências, tanto na Educação Básica quanto na Educação Superior, almeja a alfabetização científica dos estudantes, fornecendo não somente noções e conceitos científicos, mas também condições para que possam "fazer ciência", sendo defrontados com problemas autênticos nos quais a investigação seja condição para resolvê-los (SASSERON; CARVALHO, 2008, p. 335). Assim, o professor, como sujeito mais experiente, é desafiado a estar atento às informações que os estudantes trazem para a discussão, com a finalidade de identificar possíveis fragilidades e equívocos conceituais que vão sendo apresentados pelos mesmos. Além disso, muitas das informações trazidas pelos grupos de trabalho podem promover novas problematizações e, assim, desencadear um novo processo de inquirição.

Com a orientação do professor, os estudantes podem alcançar compreensões mais significativas de ideias cientificamente aceitas e direcionadas pelo currículo (SCHWARTZ; LEDERMAN; CRAWFORD, 2004, p. 612, tradução nossa). Concordamos com Carvalho et al. (2013), quando afirma que é nesse movimento de interação entre estudante-estudante-professor-objeto de estudo que a linguagem científica vai se formando. Logo, o professor poderá desafiar os seus estudantes a buscarem evidências em seus dados e/ ou informações coletadas e justificativas em suas respostas, incentivando-os a falar, a ler e a escrever durante todo o processo de busca.

Para Freire (2017), a educação problematizadora coloca em evidência a exigência da superação da contradição educador-educando. Depreende-se a necessidade do desenvolvimento de um trabalho didático-pedagógico pautado no diálogo. Isso implica que o professor necessita ser um sujeito disposto a vivenciar novas experiências, a escutar e a indagar os seus estudantes com vista ao aperfeiçoamento dos conhecimentos e, ao mesmo tempo, estar aberto à transformação das práticas de ensino na sala de aula de Ciências. 
Seguindo a perspectiva do contexto de sala de aula, a pergunta emerge como elemento essencial para o desenvolvimento de atividades investigativas. Assumimos que os processos de investigação normalmente são organizados em torno de inquietações, de interesses de quem investiga. Nas escritas dos participantes do Cirandar, encontramos a ideia de envolver os estudantes no exercício de elaboração das suas próprias perguntas sobre os fenômenos da natureza, como estratégia didática dos professores de Ciências que apostam na investigação dialógica na sala de aula.

Essa perspectiva dialógica, pautada na pergunta, é comunicada no relato de Bacelo-R34, em que apresenta a experiência vivida ao propor que os estudantes do primeiro ano do Ensino Médio construíssem perguntas sobre a temática celular.

Os grupos reunidos tiveram um tempo para analisar o material recebido e, através dele e de outros materiais que encontrassem sobre o tema proposto, os mesmos deveriam definir o problema a ser investigado através de uma pergunta, um questionamento que o grupo gostaria de saber sobre o tema núcleo (Bacelo-R34).

A partir desse excerto, registramos que não basta solicitar a um grupo de estudantes que elaborem perguntas sobre determinado tema. Para que essas possam ser elaboradas, reconhecemos que o professor autor do relato fornece aos estudantes condições para tomarem consciência de outras possibilidades do tópico em questão, uma vez que ninguém é capaz de pensar em tudo certamente; ninguém é capaz de pensar em alguma coisa sem experiência e informação sobre ela (DEWEY, 2010, p. 127). Na atividade de Bacelo-R34, esse movimento ocorre por meio da leitura de referenciais pré-selecionados pelo professor, da fala e discussão entre os estudantes. Esse entendimento da professora é observado em seu relato a contar de interlocuções teóricas com Moraes (2010) e Bueno e Schein (2015), mostrando uma perspectiva de investigação em sala de aula pautada no educar pela pesquisa.

Para Moraes, Galiazzi e Ramos (2012), o movimento de ver outras possibilidades ao desenvolver a educação em Ciências, contrastado com a consciência do nosso próprio ser e conhecer, é que dá origem ao questionamento. No Quadro 5 reproduzimos as perguntas elaboradas pelos estudantes e comunicadas por Bacelo-R34 em seu relato.

\section{Quadro 5 - Perguntas elaboradas pelos estudantes e comunicadas pela professora Bacelo-R34 em seu relato}

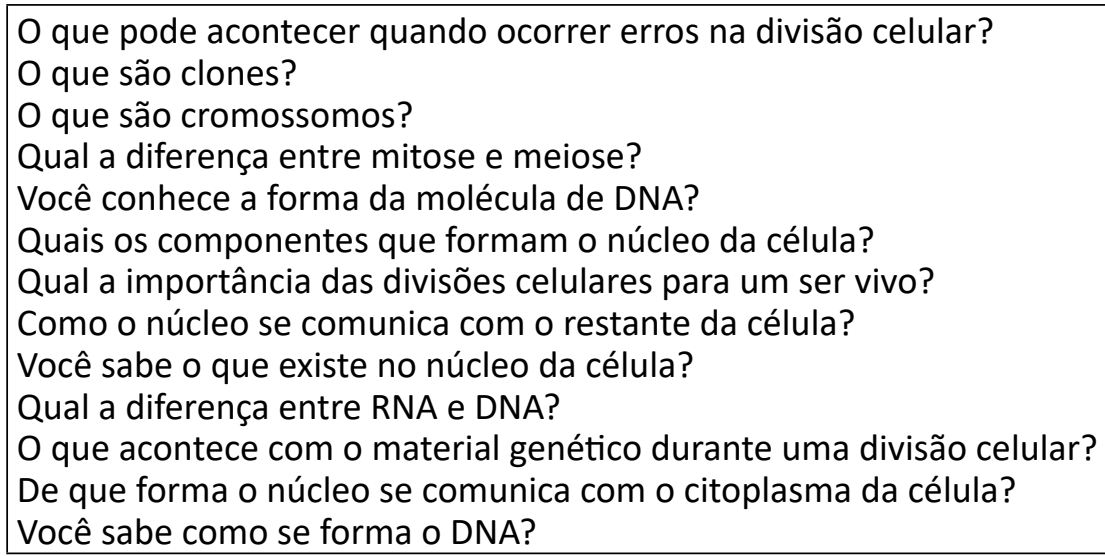


Assumimos no estudo que as perguntas elaboradas pelos estudantes se constituem em um mapeamento inicial dos conhecimentos. Para Moraes (2010), os movimentos do conhecimento se dão a contar do questionar e do pôr em dúvida o já conhecido, para, então, ir à procura de respostas que constituem reconstruções de teorias e práticas existentes (p. 140). Significamos que fazer perguntas é estar imersos em um movimento oportunizado pelo envolvimento na linguagem - leitura, fala e escrita.

Compreendemos que, independentemente de o professor utilizar a investigação em sala de aula, o ensino pode ser organizado a partir das perguntas elaboradas pelos estudantes. De acordo com Sasseron (2013), as perguntas podem ser o gatilho para a análise, mas também podem ocorrer ao longo dela, como maneira de assegurar o estudo de dados, informações e conhecimento já existentes. Encontramos essa perspectiva no relato do licenciando em Química Silva-R26, participante do Programa Institucional de Iniciação à Docência (Pibid) da Furg:

As temáticas surgiram devido perguntas feitas pelos alunos do oitavo ano do professor Cezar Motta da E. E. E. M. Mascarenhas de Moraes, onde podemos definir ao certo o que iríamos trabalhar. Havia perguntas sobre violência, clima e tecnologia. o grupo em que eu estava ficou com a temática "drogas", devido perguntas sobre violência e perguntas sobre o que eram e como eram feitas algumas drogas, como, por exemplo: cocaina, metanfetamina, cigarro, crack, dentre outras (Silva-R26).

Além disso, concordamos com Thomaz, Amaral e Ramos (2015), quando afirmam, em seu estudo, que valorizar a pergunta do aluno na dinâmica da aprendizagem permite construirmos ações pedagógicas pautadas na necessidade e nos interesses do estudante, respeitando seu conhecimento e cultura (p. 2). Para Wells (2016), o diálogo é mais propenso a se desenvolver em sala de aula quando os alunos têm experiências e ideias que querem compartilhar. Isso representa, para professores e estudantes de diferentes níveis de ensino, o desafio de superar a ideia de que nos comunicamos apenas para passar aos outros informações e conhecimentos acabados.

Considerando a análise das perguntas elaboradas pelos estudantes, Bacelo-R34 registra sua reflexão sobre as diferenças existentes entre os participantes de sua sala ao afirmar que

[...] durante a elaboração das questões observou-se situações diferenciadas entre as turmas.

A constatação da professora entra em concordância com o pensamento de Sasseron (2013), ao afirmar que a sala de aula é um ambiente complexo em que diferentes pessoas, com experiências de vida distintas, encontram-se para debater sobre temas de diversas áreas do conhecimento humano (p. 47). Desse modo, o professor é desafiado a oferecer condições para que a argumentação dos estudantes surja, conforme observado no registro:

Através das redes sociais, à medida que iam construindo o material a ser apresentado, o mesmo era enviado através de fotos para a professora para tirarem dúvidas e verificarem se estava dentro da proposta, o que mostrou o envolvimento e intera- 
ção dos mesmos fora do horário da escola. Alguns levavam para a escola para mostrar o que já tinham elaborado e percebia-se a criatividade em relação ao material utilizado e a forma como iriam apresentar (Bacelo-R34).

Reconhecemos nesse registro o interesse dos estudantes em mostrar o que estão fazendo, mesmo que fora do espaçotempo escolar. De acordo com Wells (2016), a ansiedade dos estudantes em expressar as suas construções mostra que eles estão engajados na busca por respostas a suas inquietações e reconhecem que suas contribuições têm consequências para ações futuras.

A leitura nas aulas de Ciências é outro aspecto interessante para o desenvolvimento do pensamento científico, e se mostra nas escritas dos professores em análise neste estudo. Para Sedano (2013), por meio da leitura podemos aumentar e aprofundar conhecimentos sobre determinado campo cultural ou científico, ampliar nosso vocabulário pessoal e, consequentemente, interferir na reflexão e construção do discurso. No trabalho de Chimieski-R1, encontramos a leitura de textos de divulgação científica no ambiente escolar como meio de desafiar os estudantes a refletir sobre a discussão proposta, pensar criticamente e assumir posição com base nos textos e em seus conhecimentos prévios.

[...] procurei construir uma metodologia que buscasse despertar a atenção e a participação da classe. Assim, a partir de textos lacunados, comecei a trabalhar habilidades como o raciocínio, a atenção e a memória. A estratégia consistia em não fornecer conceitos prontos para a turma, mas possibilitar, através de questionamentos envolvendo seu conhecimento empírico, a formulação de hipóteses sobre o assunto em questão (Chimieski-R1).

No excerto observamos que a leitura proposta oferece desafios aos estudantes, explorando os seus conhecimentos e estimulando a formulação de questionamentos e hipóteses. De acordo com Sedano (2013), nas aulas de Ciências, que têm por objetivo a problematização e o ensino por meio da investigação, a utilização de textos tem a função de aproximar o estudante dos conceitos científicos. Essa aproximação, na concepção de Demo (1997), entretanto, precisa vir acompanhada de estratégias metodológicas para que os estudantes façam interpretações próprias, substituindo, assim, a conduta passiva pela crítica e construção de posicionamentos alternativos para que se passe da posição de "informado" à de informante, informativo, informador (Ibidem, p. 24).

Nesse processo, o questionamento reconstrutivo mostra-se fundamental nos procedimentos metodológicos em que a investigação é assumida como princípio educativo. Na escrita de Mugica-R15, as perguntas de estudantes da educação infantil provocaram o professor a criar um espaçotempo em sala de aula que simulasse uma praça pública, contemplando uma área verde abrigando caracóis. Significamos que a indagação oportuniza o constituir de novas experiências em sala de aula.

Nesse sentido, a praça da Santa Casa de Caridade de Bagé/RS foi cenário das descobertas da ação das crianças neste projeto. A mesma, localizada no entorno da escola, contempla no jardim e árvores ao redor inúmeros caracóis que estão à disposição dos pequenos enquanto brincam, gerando inúmeros questionamentos como "Dentro do caracol tem lesma?", "O caracol mora numa concha?" [...]. Com a ideia de fazer o espaço de Ciências imaginando que este é uma "praça" e que é 
um lugar que pode contemplar inúmeros bichinhos de jardim, é que neste caso meu propósito foi que a lupa, o jaleco e o microscópio entrassem em ação nas mãos das crianças (como "biólogos" de faz de conta) investigando o caracol (Mugica-R15).

Por intermédio do diálogo, o professor desafia os estudantes a pensarem sobre o fenômeno (a vida do caracol), superando, desse modo, a simples ideia da manipulação de objetos. Capps e Crawford (2012) asseveram que ensinar as crianças a fazer investigações científicas desafia os professores a envolver os estudantes em práticas que se aproximam das realizadas pelos cientistas. A investigação como abordagem de ensino abrange, também, mostrar aos estudantes a ciência como um esforço humano, dirigido pela teoria e cultura, dependente da observação empírica e sujeita a mudanças (SCHWARTZ; LEDERMAN; CRAWFORD, 2004, p. 612, tradução nossa).

O partilhar ideias envolve o engajamento disciplinar dos estudantes do professor Mugica-R15, potencializado pela curiosidade, característica própria dos estudantes desse nível escolar, o que possibilita a elaboração e a reelaboração de explicações sobre a vida dos caracóis. De acordo com Freire (2014), a produção do conhecimento sobre o objeto implica exercício da curiosidade. Analisamos ser fundamental que essa curiosidade leve estudantes e professores a se preocuparem com um determinado tema, mediado pelo diálogo e pela indagação. Nas palavras de Paulo Freire, o que importa é que os professores e estudantes se assumam epistemologicamente curiosos.

Registramos, na análise do texto de Mugica-R15, que, ao criar um ambiente lúdico e estimulante, os estudantes começaram a fazer várias tentativas para buscar respostas às suas inquietações.

As crianças começaram a ficar preocupadas com a alimentação do caracol. E também foi aquela preocupação com os cuidados. Umedecer a terra foi o primeiro levantamento de hipóteses que o F. comentou e que, de fato, estávamos fazendo quase todos os dias. Depois eles estavam intrigados em como alimentá-lo e a primeira experiência foi experimentar a alface e também umedecer a terra, a folha e os galhos para oferecer aos caracóis um habitat confortável e próximo do real que é o jardim (Mugica-R15).

Assumimos, a contar do estudo de Thomaz, Amaral e Ramos (2015), que a pergunta do estudante emerge como possibilidade de identificar a transição do conhecimento cotidiano ao conhecimento científico (p. 7). Além disso, registramos que a interação em sala de aula não se define apenas pela comunicação entre o professor-estudante e o estudante-estudante. Seguindo as ideias de Carvalho et al. (2013), a interação igualmente depende do ambiente em que a comunicação ocorre, de modo que o aprendiz interage também com os problemas, os assuntos, a informação e os valores culturais dos próprios conteúdos com os quais estão trabalhando em sala de aula (p. 4). Isto significa reconhecer que aprender ciências, por intermédio da investigação, implica um conjunto de interações que abrange a proposição de pensamentos e o operar com informações e com a linguagem científica.

Desse modo, admitimos que construímos significados por intermédio do uso da linguagem. Em Lemke (1997), compreendemos que a linguagem é parte da semiótica e está voltada ao estudo de [...] todos os sistemas de signos e símbolos (incluindo gestos, imagens, falas, escritas, etc.) e de como estes são empregados para comunicar e 
expressar significados (p. 195, tradução nossa). Isso implica que atribuímos significados às nossas reflexões por intermédio das palavras que utilizamos para descrever ações socialmente significativas.

Assumimos ser por meio da linguagem que nossas vivências e experiências se convertem em conhecimento (MORAES, 2010, p. 137). Essa perspectiva de uso da linguagem no processo de investigação entra em concordância com o excerto de Pereira-R30:

Assim, a partir da discussão em grupo sobre os textos produzidos, a Aluna 10, T9B, passou a narrar a sua experiência em viver em uma comunidade, em uma cidade próxima à nossa, na qual a energia elétrica dependia de duas usinas a óleo diesel, há não muito tempo, na década de 1990 (Pereira-R30).

A professora traz no referido relato a perspectiva de considerar, em sala de aula, os interesses dos estudantes, a contar de suas escritas sobre determinado tópico da disciplina de Física:

[...] a primeira tarefa das turmas foi a produção de um texto sobre a Energia Elétri$c a$, como o intuito de obter informações sobre como os mesmos a compreendiam, qual a relevância da mesma no cotidiano e na sociedade atual (Pereira-R30).

Observamos, neste contexto, que a escrita dos estudantes é assumida pelo professor não como um produto acabado, mas como uma estratégia de organização das ações e das conversas a serem realizadas em sala de aula.

$\mathrm{Na}$ perspectiva dialógica da investigação assumimos a escrita em sala de aula como uma oportunidade de os estudantes estabelecerem associações e elaborarem enunciados, oportunizando a eles refletirem sobre os seus pensamentos e fenômenos da natureza. Registra-se que a língua falada, embora seja uma dialética necessária e eficiente para compartilhar ideias e estimular o pensar, não é suficiente, devendo ser acompanhada pela linguagem escrita (YORE; HAND; FLORENCE, 2004, p. 339).

Organizar o ensino dessa forma significa aceitar que os processos de ensinar e aprender não podem ser planejados de forma linear, mas que se dão por auto-organização, exigindo desorganização para que possam emergir novas formas de organização (MORAES, 2010, p. 145). Isso não significa realizar em sala de aula apenas aquilo que os estudantes gostariam de fazer. Na escrita de Pereira-R30 observamos um professor preocupado em selecionar, na parceria com os seus estudantes, informações relevantes para o desenvolvimento da disciplina:

Com as produções em mãos, iniciei a leitura dos textos e em cada um deles marquei frases que seriam excelentes para o debate em sala de aula. [...] Os excertos foram lidos diante das turmas, as quais foram convidadas a agruparem os excertos por semelhanças, definindo as categorias emergentes dos textos (Pereira-R30).

Significamos, neste momento da análise, que a linguagem, escrita e oral, se mostra como meio de atribuir e fundamentar significados. Por intermédio da linguagem escrita os estudantes expressam experiências, desejos e inquietações que são trazidas pelo professor ao desenvolver novas experiências no âmbito da sala de aula. Além disso, de acordo com Yore, Hand e Florence (2004), a linguagem é um meio de fazer ciência e de construir alegações científicas, e um fim em virtude de seu uso para comunicar as 
perguntas, procedimentos e compreensões para outras pessoas. Ao considerar essas ações em sala de aula, os professores estão fornecendo condições para que os estudantes possam alcançar a alfabetização científica.

Esse movimento pode ser reconhecido na interlocução com a escrita de Pereira-R30, quando afirma:

Percebi alunos que não sabiam como pronunciar a unidade de potência elétrica, que se expressa em W (Watts) e liam como Volt (V); demonstraram a sua compreensão e passaram a não confundir a leitura da mesma com a unidade de tensão elétrica (V).

Ainda, destaca que

[...] ao longo do processo foram deixados espaços para que os alunos, com suas experiências vividas, fossem os preenchendo, trazendo seus saberes construídos ao longo do cotidiano, saberes de suas experiências profissionais e dúvidas sobre conceitos básicos da Eletricidade, formando a marca de reflexão na sala de aula (Pereira-R30).

No relato de Pereira-R38 observamos que Ambientes Virtuais de Aprendizagem (AVA) podem oportunizar aos estudantes e professores explorarem os fenômenos da natureza de diversas formas. A professora compartilha a experiência de trabalhar em um AVA suportado na plataforma Grassp do projeto Global On-line Science Labs for Inquiry Learning at School (Go-Lab). No referido ambiente estudantes e professor estudam circuitos elétricos operando "com simulações, vídeos, chat e escrita colaborativa em um espaço ampliado" (Pereira-R38).

Essa perspectiva, apontada no relato de Pereira-R38, encaminha-nos para os processos de investigação da sala de aula que contemplem a linguagem semiótica. Concordamos com Lemke (2006), quando ensina que também aprendemos com representações visuais de diversos tipos, tais como simulações virtuais, desenhos, filmes, imagens, entre outros. Logo, ensinar Ciências também é aprender a combinar diferentes meios de comunicação e as múltiplas representações. A referida proposição desafia os professores a apoiarem os seus estudantes a pensarem sobre os fenômenos da natureza integrando diferentes recursos linguísticos, matemáticos e visuais que abrangem simulações virtuais e ambientes interativos (LEMKE, 2006).

Compreendemos, a contar desses registros, que a linguagem emerge como um sistema, usado ativamente para gerar e consolidar novos entendimentos. Para Bravo e Chion (2017), os estudantes não só devem entender os principais conceitos implicados nas teorias e modelos científicos, mas também o vocabulário científico, e serem capazes de aplicar as estruturas e padrões de linguagem necessários. Aprender Ciências envolve aprender a falar sobre Ciências (LEMKE, 1997). Isso quer dizer que os estudantes precisam ser motivados a avançar na autonomia da expressão própria (DEMO, 1997), que abrange a produção de textos, a capacidade de se expressar, de tomar iniciativa, de construir espaços próprios, de fazer-se presente e participativo.

A investigação dialógica em sala de aula, nesta categoria de análise, sinaliza a importância de os estudantes comunicarem as compreensões construídas ao falar sobre Ciências. De acordo com Moraes, Galiazzi e Ramos (2012), a construção de argumentos 
e a comunicação estão estreitamente relacionadas, uma vez que as novas verdades precisam ser debatidas e criticadas se para tornarem cada vez mais fortes. Registramos que comunicar compreensões é um movimento próprio do fazer Ciências, uma vez que faz parte do trabalho colocar em discussão as ideias, no sentido de aperfeiçoar e/ou tomar novos rumos na construção do conhecimento.

Nos relatos dos professores a comunicação mostra-se de duas formas: a primeira consiste em comunicações que acontecem dentro da própria sala de aula por intermédio de interações discursivas, desenhos, apresentações orais, escritas, entre outras. A segunda forma que se mostra é um movimento que vai além do espaçotempo da sala de aula, como acontece em Feiras e Mostras de Ciências. Nos relatos de Soares-R24 e Motta-R29, além dos aspectos já evidenciados ao longo desta escrita, encontramos a comunicação de compreensões para fora do espaçotempo da sala de aula em que ocorreu a investigação.

A respeito da feira de Ciências, no relato de Soares-R24 ela emerge como possibilidade de unir o lúdico, a investigação e o conhecimento das Ciências em sala de aula.

Percebi esta interação de alunos, conteúdos programáticos e comunidade escolar na feira de ciências, onde, a partir do questionamento "Você tem medo de quê?", do início, na construção para a Feira de Ciências com os educandos das turmas do Ensino Médio da Escola Dr. Augusto Duprat na disciplina de Biologia, onde as inquietações foram diversas, percebemos que estávamos diante de um projeto instigador e envolvente que contempla os sujeitos inseridos naquele espaço educativo. Começamos, primeiro, na perspectiva do lúdico/suspense, onde os alunos seriam os personagens de filmes de terror, como Zumbis, Bruxas, Vampiros (Soares-R24, grifo nosso).

Assumimos que as feiras de Ciências nas escolas oportunizam a estudantes e professores o desenvolvimento de projetos de investigação para atender as necessidades internas ou externas à escola, a fim de buscar a solução para um problema e adquirir um novo conhecimento, tendo sempre em vista a melhoria do sistema educacional. Ressaltamos, entretanto, que o mais importante não é o produto final, mas, sim, o processo que potencializou o desenvolvimento do projeto. Nesse sentido, concordamos com Moraes, Galiazzi e Ramos (2012) de que é fundamental destacarmos produtos para a construção da habilidade de questionar, de construir argumentos com qualidade e de saber comunicar os resultados à medida que são produzidos.

O conjunto de aspectos destacados nesta quarta categoria de análise possibilita significar a investigação dialógica na sala de aula de Ciências. A partir deste conjunto de indicativos emergentes, argumentamos que a investigação dialógica se mostra como estratégia didático-pedagógica desencadeada pela problematização, com questionamentos dos estudantes e professores ao operar, de forma coletiva, informações e linguagem científica no constituir, negociar e comunicar significados na sala de aula de Ciências.

O referido argumento evidencia a investigação como estratégia didático-pedagógica que desafia ações de colaboração e de diálogo entre professores e estudantes. Desse modo, é por intermédio do diálogo em sala de aula que os estudantes constroem e 
reconstroem entendimentos acerca da Ciências. Isso requer adoção de estratégias de ensinar e aprender que oportunizem diferentes modos de engajamento aos estudantes para expressarem as suas compreensões.

\section{CONSIDERAÇÕES FINAIS}

Apresentamos, nesta escrita, compreensões construídas acerca da investigação dialógica na sala de aula de Ciências, a contar de um processo de análise auto-organizado pela ATD. O campo empírico, constituído por 43 relatos produzidos por professores do campo das Ciências da Natureza em formação no projeto de extensão Cirandar, oportunizou compreender que o potencial pedagógico da investigação em sala de aula reside nas ações dos professores em problematizar com os seus estudantes os fenômenos, explorando informações, fazendo relações disciplinares e contextualizando os saberes abordados.

Seguindo este entendimento, a investigação, enquanto estratégia didático-pedagógica, apresenta-se como instrumento metodológico para a construção do conhecimento. No contexto da sala de aula de Ciências, significa envolver os estudantes em ações de indagação e pesquisa em torno do tema/tópico que se objetiva conhecer. A análise no estudo mostra-nos que a investigação por meio de problemas a serem resolvidos favorece o desenvolvimento da argumentação dos estudantes em sala de aula. As interlocuções com os relatos dos professores e teóricos indicam-nos que a investigação dialógica em sala de aula pode acontecer em diferentes atividades desde que os estudantes sejam desafiados a observar, indagar, experimentar, ler, escrever e falar para/ com outras pessoas sobre o que lhes interessa.

Logo, compreendemos a investigação na sala de aula de Ciências como uma oportunidade de envolver os estudantes em um movimento coletivo de construção de conhecimento, uma vez que a construção do conhecimento pode acontecer em diferentes perspectivas, mas todas são, por natureza, essencialmente sociais e dialógicas (WELLS, 2016). Nessa perspectiva, aprendizagem por meio da investigação acontece com o envolvimento ativo e de diálogo dos estudantes e professores desde a sala de aula, possibilitando transformações nas formas de ensinar e aprender Ciências.

A seguir destacamos aspectos emergentes do campo empírico e teórico acerca da investigação enquanto estratégia didático-pedagógica na sala de aula de Ciências.

- A partir da problematização, processos de investigação em sala de aula podem ser desencadeados.

- A educação problematizadora em torno de um objeto aperfeiçoável desafia estudantes e professores a constituírem coletivos de indagação e investigação.

- A investigação em torno de um objeto aperfeiçoável oportuniza aos estudantes desenvolverem a criticidade coletiva ao pensarem os seus mundos.

- A investigação, enquanto estratégia didático-pedagógica, desafia o professor a ser um sujeito disposto a vivenciar novas experiências, a escutar e problematizar, visando o aperfeiçoamento dos conhecimentos.

- A pergunta em sala de aula como elemento fundante para a investigação em sala de aula. 
- Fazer perguntas é estar imerso em um movimento oportunizado pela linguagem.

- A indagação em sala de aula oportuniza a construção de novas experiências.

- Aprender Ciências, mediada pela investigação, implica um conjunto de interações que abrange a proposição de pensamentos e o operar com informações e com a linguagem científica.

- A linguagem escrita e oral mostra-se como meio de constituir e negociar significados.

A partir do conjunto de aspectos emergentes, a investigação, enquanto estratégia didático-pedagógica, mostrou-se dialógica quando permeada pela problematização ao operar, de forma coletiva, as informações e a linguagem científica na sala de aula de Ciências. A investigação, pautada no diálogo e na busca por respostas às inquietações, desafia professores e estudantes a envolverem-se num movimento de fala, leitura e escrita científica. Além disso, as escritas dos professores mostram que a investigação em sala de aula os desafiam a ser sujeitos dispostos a vivenciar novas experiências, a escutar e indagar seus estudantes, aperfeiçoando, assim, seus conhecimentos profissionais.

\section{REFERÊNCIAS}

ALVES, N. Decifrando o pergaminho os cotidianos das escolas nas lógicas das redes cotidianas. In: GARCIA, A.; OLIVEIRA, I. B. (org.). Nilda Alves: praticantepensante de cotidianos. 1. ed. Belo Horizonte: Autêntica, p. 133-151. Coleção perfis da Educação. 2015.

BARBOSA, S. M. C.; BARBOSA, J. G. Etnometodologia multirreferencial: contribuições teórico epistemológicas para a formação do professor-pesquisador. Educação \& Linguagem, v. 11, n. 18, p. 238-256, 2008. BICUDO, M. A. V. Pesquisa qualitativa segundo a visão fenomenológica. São Paulo: Cortez. 2011. 150 p. BRAVO, A. A.; CHION, A. R. Language, Discourse, Argumentation, and Science Education. In: Science Education. Brill Sense, p. 157-166, 2017.

BUENO, J. B. M.; SCHEIN, Z. P. Educar pela pesquisa: prática de construção e reconstrução do conhecimento científico. Faculdades Integradas de Taquara-Faccat, RS. 2015. Disponível em: https://www2.faccat.br/ portal/sites/default/files/EDUCAR\%20PELA\%20PESQUISA_1.pdf. Acesso em: fev. 2019.

CAPPS, D. K.; CRAWFORD, B. A. Inquiry-based instruction and teaching about nature of science: are they happening? Journal of Science Teacher Education, v. 24, n. 3, p. 497-526, 2012.

CARVALHO, A. P. C. et al. Ensino de Ciências por investigação: condições para implementação em sala de aula. São Paulo: Cengage Learning, 2013. p. 1-20.

DELIZOICOV, D. Problemas e problematizações. Ensino de Física: conteúdo, metodologia e epistemologia numa concepção integradora. Florianópolis: Ed. da UFSC, 2001.

DEMO, P. Pesquisa e construção de conhecimento: metodologia científica no caminho de Habermas. Rio de Janeiro: Tempo Brasileiro, 1997.

DEWEY, J. A arte como experiência. Trad. Vera Ribeiro. São Paulo: Editora Martins, 2010.

DINIZ-PEREIRA, J. E.; LACERDA, M. P. Possíveis significados de pesquisa na prática: ideias para fomentar o debate. Educação \& Sociedade, v. 30, n. 109, 2009.

DUHALDE, M. A. La investigación en la escuela. 1. ed. Buenos Aires, Argentina: Novedades Educativas, 1999.

FERREIRA, A. B. Dicionário Aurélio da Língua Portuguesa. 5. ed. Curitiba: Editora Positivo, 2010.

FREIRE, P. Pedagogia da autonomia: saberes necessários à prática educativa. 49. ed. Rio de Janeiro: Paz e Terra. 2014. 143 p.

FREIRE, P. Pedagogia do oprimido. 64. ed. Rio de Janeiro: Paz e Terra, 2017. 253 p.

LEMKE, J. Aprender a hablar ciencia: lenguaje, aprendizaje y valores. 1. ed. Barcelona: Paidós Ibérica, 1997. 273 p. 
LEMKE, L. Investigar para el futuro de la educación científica: nuevas formas de aprender, nuevas formas de vivir. Enseñanza de las Ciencias: Revista de Investigación y Experiencias Didácticas, v. 24, n. 1, p. 5-12, 2006.

MACEDO, R. S. Etnopesquisa crítica: etnopesquisa formação. 2. ed. Brasília: Liber Ars. 2010. 179 p.

MORAES, R. O significado do aprender: linguagem e pesquisa na reconstrução de conhecimentos. Conjectura: Filosofia e Educação, v. 15, n. 1, 2010.

MORAES, R.; GALIAZZI, M. C. Análise textual discursiva. 3. ed. Ijuí: Editora Unijuí, 2016. 264 p.

MORAES, R.; GALIAZZI, M. C.; RAMOS, M. G. Pesquisa em sala de aula: fundamentos e pressupostos. In: MORAES, R.; LIMA, Valderez M. do R. Pesquisa em sala de aula: tendências para a educação em novos tempo. 3. ed. Porto Alegre: EdipUCRS, 2012. p. 11-21.

RICARDO, E. C. Problematização e contextualização no ensino de Física. In: CARVALHO, A. M. P. et al. (org.). Ensino de Física. 1. ed. São Paulo: Cengage Learning, 2010. p. 29-53.

SÁ, E. F.; LIMA, M. E. C.; AGUIAR JR., O. A construção de sentidos para o termo ensino por investigação no contexto de um curso de formação. Investigações em Ensino de Ciências, v. 16, n. 1, p. 79-102, 2011.

SASSERON, L. H. Interações discursivas e investigação em sala de aula: o papel do professor. Ensino de ciências por investigação: condições para implementação em sala de aula. São Paulo: Cengage Learning, 2013. p. 41-62.

SASSERON, L. H.; CARVALHO, A. M. P. Almejando a alfabetização científica no ensino fundamental: a proposição e a procura de indicadores do processo. Investigações em ensino de ciências, v. 13, n. 3, p. 333352, 2008.

SCHWARTZ, R. S.; LEDERMAN, N. G.; CRAWFORD, B. A. Developing views of nature of science in an authentic context: An explicit approach to bridging the gap between nature of science and scientific inquiry. Science Education, v. 88, n. 4, p. 610-645, 2004.

SEDANO, L. Ciências e leitura: um encontro possível. In: CARVALHO, A. M. P. et al. (org.). Ensino de ciências por investigação: condições para implementação em sala de aula. 1. ed. São Paulo: Cengage Learning, 2013. p. 77-93.

SOLINO, A. P.; GEHLEN, S. T. O papel da problematização freireana em aulas de ciências/física: articulações entre a abordagem temática freireana e o ensino de ciências por investigação. Ciência \& Educação, v. 21, n. 4, p. 911-930, 2015.

THOMAZ, E.; AMARAL, L. C.; RAMOS, M. G. As perguntas dos estudantes: uma possibilidade de identificar a transição do conhecimento cotidiano para o científico. ENCONTRO NACIONAL DE PESQUISADORES EM EDUCAÇÃO EM CIÊNCIAS, 10., 2015. Águas de Lindóia. Anais [...]. São Paulo, Brasil, 2015.

WELLS, G. Aprendizagem dialógica: o processo dos seres humanos de falar em direção à compreensão. In: GALIAZZI, M. C. et al. Indagações dialógicas com Gordon Wells. 1. ed. Rio Grande: Furg, 2016. p. 47-85.

YORE, D.; HAND, M.; FLORENCE, K. Scientists' views of science, models of writing, and science writing practices. Journal of Research in Science Teaching, v. 41, n. 4, p. 338-369, 2004. 